\title{
Inhibition of thrombin generation in human plasma by phospholipid transfer protein
}

Hiroshi Deguchi ${ }^{*}$, Gertrud Wolfbauer ${ }^{2}$, Marian C. Cheung ${ }^{2}$, Yajnavalka Banerjee ${ }^{1,3}$, Darlene J. Elias ${ }^{1}$, José A. Fernández ${ }^{1}$, John J. Albers ${ }^{2}$ and John H. Griffin ${ }^{1}$

\begin{abstract}
Background: Plasma phospholipid transfer protein (PLTP) transfers lipids between donors and acceptors (e.g., from $\mathrm{HDL}$ to VLDL) and modulates lipoprotein composition, size, and levels. No study has reported an assessment of the effects of PLTP on blood clotting reactions, such as reflected in thrombin generation assays, or on the association of venous thrombosis (VTE) risk with PLTP activity.

Methods: The in vitro effects of PLTP on blood coagulation reactions and the correlations between plasma PLTP activity levels and VTE were studied.

Results: Recombinant (r) PLTP concentration-dependently inhibited plasma thrombin generation and factor XII-dependent kallikrein generation when sulfatide was used to stimulate factor XII autoactivation in plasma. However, rPLTP did not inhibit thrombin generation in plasma induced by factor Xla or tissue factor, implicating an effect of PLTP on contact activation reactions. In purified systems, rPLTP inhibited factor XII autoactivation stimulated by sulfatide in the presence of VLDL. In surface plasmon resonance studies, purified factor XII bound to immobilized rPLTP, implying that rPLTP inhibits factor XII-dependent contact activation by binding factor XII in the presence of lipoproteins. Analysis of plasmas from 40 male patients with unprovoked VTE and 40 matched controls indicated that low PLTP lipid transfer activity ( $\leq 25$ th percentile) was associated with an increased risk of VTE after adjustment for body mass index, plasma lipids, and two known thrombophilic genetic risk factors.
\end{abstract}

Conclusion: These data imply that PLTP may be an antithrombotic plasma protein by inhibiting generation of prothrombotic factor XIla in the presence of VLDL. This newly discovered anticoagulant activity of PLTP merits further clinical and biochemical studies.

Keywords: Phospholipid transfer protein, Factor XII, Venous thromboembolism, Thrombin generation

\section{Background}

The blood coagulation system is triggered by either the intrinsic or extrinsic pathway and involves sequential enzymatic activations of serine protease zymogens enhanced by non-enzymatic cofactors, factors Va and VIIIa, resulting in generation of thrombin $[1,2]$. Thrombin generation is central to the regulation of hemostasis and thrombosis and to the pathogenesis of cardiovascular disease and venous thrombosis. The intrinsic pathway is triggered by contact activation. Recent studies using mouse thrombosis models suggest that the intrinsic pathway is

\footnotetext{
*Correspondence: dhiroshi@scripps.edu

${ }^{1}$ Department of Molecular and Experimental Medicine, The Scripps Research Institute, MEM180, 10550 North Torrey Pines Rd., La Jolla, CA 92037, USA

Full list of author information is available at the end of the article
}

essential for pathological thrombus formation in both the arterial [3-7] and venous systems [7]. The "contact activation" of plasma involves 3 zymogens, factor XII, factor XI and prekallikrein, plus a non-enzymatic cofactor, high molecular weight kininogen, that participate in a set of interrelated proteolytic activation reactions [4, 8-15]. During the initial stages of contact activation, factor XII and prekallikrein participate in reciprocal proteolysis in which factor XIIa activates prekallikrein to kallikrein, which in turn converts factor XII into factor XIIa. Activation of factor XII can be enhanced by autoactivation of zymogen factor XII by the active form $\alpha$-factor XIIa. These reactions are accelerated by negatively charged surfaces (e.g., kaolin, sulfatides, and dextran sulfate).
C Biomed Central

(c) 2015 Deguchi et al. This is an Open Access article distributed under the terms of the Creative Commons Attribution License (http://creativecommons.org/licenses/by/4.0), which permits unrestricted use, distribution, and reproduction in any medium, provided the original work is properly credited. The Creative Commons Public Domain Dedication waiver (http://creativecommons.org/publicdomain/zero/1.0/) applies to the data made available in this article, unless otherwise stated. 
Plasma lipids and lipoproteins can influence both procoagulant and anticoagulant reactions $[16,17]$. Furthermore, dyslipidemia and dyslipoproteinemia are associated with hypercoagulability and venous thromboembolism (VTE) $[16,17]$. The lipid transfer protein, cholesteryl ester transfer protein (CETP), which carries and transfers lipids to modulate plasma lipoprotein levels, can exert procoagulant activity by enhancing prothrombinase activity in purified systems [18]. Furthermore, plasma CETP mass level was correlated with relative hypercoagulability of plasma independent of high density lipoprotein (HDL) levels. Although molecular mechanisms for CETP procoagulant activity remain unclear, we hypothesized that other lipid transfer proteins can also affect blood coagulation.

Plasma phospholipid transfer protein (PLTP), a homolog of CETP, circulates in plasma and facilitates the transfer of phospholipids and cholesterol among lipoproteins [19-27]. It can mediate the conversion of HDL into larger and smaller particles $[28,29]$ and generate pre- $\beta$ HDL in the process [30]. PLTP also transfers phospholipids from very low density lipoprotein (VLDL) to HDL by PLTP shuttling from HDL to VLDL particles [31]. In clinical studies, high PLTP activity was reported to be associated with the increased risk of coronary artery disease [32, 33], notably in statin-treated patients [34]. In contrast, low PLTP activity was reported to be associated with peripheral atherosclerosis [35], suggesting that the relationship of plasma levels of PLTP activity to cardiovascular risk is controversial [32-38]. No study has reported an assessment of the effects of PLTP on blood clotting reactions, such as reflected in thrombin generation assays, or on the association of VTE risk with PLTP activity.

Here we report that PLTP can inhibit sulfatide-induced contact activation of thrombin generation, that factor XII binds directly to PLTP, and that low plasma PLTP activity levels may be associated with VTE risk.

\section{Methods}

\section{Materials}

Fatty acid-free bovine serum albumin (BSA) was purchased from Calbiochem (San Diego, CA). Human factor $\mathrm{XIa}$ and corn trypsin inhibitor were from Hematologic Technologies Inc. (Essex Junction, VT). Human factor XII, prekallikrein and kallikrein were from Enzyme Research Laboratories (South Bend, IN). Human $\alpha$-factor XIIa was from Aniara (Mason, OH). VLDL was purchased from Intracel (Frederic, MD). Sulfatide was obtained from Matreya (Pleasant Gap, PA). Kaolin was from Fisher Scientific Inc. (Pittsburgh, PA) and dextran sulfate was from GE Healthcare (Parsippany NJ). Innovin was from DADE (BioMerioeux). Chromogenic substrate S2302 and fluorogenic substrate I-1140 were obtained from Chromogenix (Franklin, $\mathrm{OH}$ ) and Bachem Bioscience
Inc. (King of Prussia, PA), respectively. Normal human pooled plasma was prepared using blood obtained from 20 adult healthy donors (10 males and 10 females) by routine venipuncture from the Scripps General Clinical Research Center's (GCRC) blood donation program after an overnight fast. Blood was mixed with $0.129 \mathrm{M}$ sodium citrate at 1:9 ratios. Plasma was prepared by centrifugation at $2,000 \times \mathrm{g}$ for $20 \mathrm{~min}$ at room temperature from each donor and pooled. The pooled normal human plasma was stored at $-80{ }^{\circ} \mathrm{C}$. Blood from VTE patients was collected in the GCRC at least 3 months after VTE diagnosis and after a $12 \mathrm{~h}$ fast.

\section{Recombinant (r) PLTP}

Recombinant wild-type PLTP was made and characterized as full length molecules as reported [29, 39]. Briefly, rPLTP was isolated by $\mathrm{Ni}^{2+}$-nitrilotriacetic acid resin column chromatography from serum-free conditioned culture medium collected from baby hamster kidney cells transfected with a His-tagged human rPLTP cDNA using methotrexate as selection agent. The isolated rPLTP fractions were assayed for phospholipid transfer activity and evaluated for purity by SDS-PAGE. The concentration of rPLTP was determined by the absorbance at $280 \mathrm{~nm}$. rPLTP was stabilized by adding phosphatidylcholine vesicles in Tris-buffered saline (TBS) containing $0.05 \mathrm{M}$ Tris, $0.15 \mathrm{M}$ $\mathrm{NaCl}, \mathrm{pH}$ 7.4. The same buffer containing the same concentration of phosphatidylcholine vesicles without rPLTP was used as control for activity assays.

\section{Preparation of sulfatide vesicles}

Sulfatide vesicles were prepared by sonication and stored up to two days. Briefly, $1 \mathrm{mg} / \mathrm{ml}$ bovine sulfatide in TBS was sonicated 5 times for $30 \mathrm{~s}$ with $1 \mathrm{~min}$ intervals using the ultrasonic processor XL (Heat System, Inc., Farmingdale, NY) under the flow of $\mathrm{N}_{2}$.

\section{Thrombin generation assay in plasma}

Plasma thrombin generation assays were performed as described with some modifications [40]. Pooled normal human plasma ( $30 \mu \mathrm{l})$ was incubated with various rPLTP concentrations for $15 \mathrm{~min}$ at $37^{\circ} \mathrm{C}$. Then, tissue factor (Innovin, final $4 \mathrm{pM}$ ) or sulfatide vesicles containing $30 \mathrm{mM} \mathrm{CaCl} 2$ and fluorogenic thrombin substrate solution (I-1140) was added to the plasma mixture (total $110 \mu \mathrm{l}$ ) to initiate coagulation activation. In factor XIa $(0.13 \mathrm{nM}$, final) -induced thrombin generation assays, corn trypsin inhibitor $(50 \mu \mathrm{g} / \mathrm{ml}$, final $)$ was also pre-incubated with plasma. Thrombin generation was followed continuously using SPECTRAmax GEMINI XS fluorometer (Molecular Devices, Sunnyvale, CA) with excitation and emission wavelengths set at 360 and $460 \mathrm{~nm}$, respectively. The first derivative of fluorescence versus time was used to produce thrombin generation curves. 


\section{Kallikrein generation assay in plasma}

The generation of plasma kallikrein in the presence of sulfatide was determined as described with some modifications [8]. Briefly, plasma (1:100, final dilution) was incubated with PLTP for $15 \mathrm{~min}$ at room temperature, followed by the addition of sulfatide $(0.5 \mu \mathrm{M}$, final $)$ and then incubated at various times. Kallikrein amidolytic activity was measured by hydrolysis of the kallikrein amidolytic substrate, S2302 (0.4 mM, final). Soy bean trypsin inhibitor $(500 \mu \mathrm{g} / \mathrm{ml}$, final), which inhibits kallikrein activity, inhibited S2302 hydrolysis in this assay system by approximately $95 \%$, whereas corn trypsin inhibitor, which specifically inhibits factor XIIa, inhibited S2302 hydrolysis by $5 \%$ (data not shown). These showed that the S2302 hydrolysis by contact phase activation in this plasma assay system mainly reflects kallikrein generation rather factor XIIa generation due to the different reactivities of kallikrein and factor XIIa with the substrate [13].

\section{Factor XII activation in purified protein system}

For factor XII autoactivation assays, factor XII $(0.1 \mu \mathrm{M}$, final) was pre-incubated with rPLTP in the presence or absence of VLDL ( $25 \mu \mathrm{g}$ protein/mL, final) for $15 \mathrm{~min}$ at room temperature, and then sulfatide vesicles $(0.5 \mu \mathrm{M}$, final) were added to start autoactivation of factor XII. S2302 (0.4 mM, final) was added at various time points and the amidolytic activity of factor XIIa was measured $[8,9]$.

Activation of factor XII by kallikrein was measured as described [10]. The reaction mixture containing factor XII $(0.1 \mu \mathrm{M}$, final $)$ with or without $\operatorname{rPLTP}(5 \mu \mathrm{g} / \mathrm{mL}$, final) in the presence or absence of VLDL $(25 \mu \mathrm{g}$ protein/mL, final) was pre-incubated for $15 \mathrm{~min}$ at $37{ }^{\circ} \mathrm{C}$, followed by the addition of kallikrein $(0.4 \mathrm{nM}$, final) and incubated for optimal time. The reaction was stopped by adding soybean trypsin inhibitor $(500 \mu \mathrm{g} / \mathrm{ml}$ final) to block kallikrein. The generated factor XIIa activity was measured as amidolytic activity for S2302 (0.4 mM, final).

\section{Prekallikrein activation by factor XIla}

Activation of prekallikrein by factor XIIa was measured as described [12]. The reaction mixture containing prekallikrein $(0.25 \mu \mathrm{M}$, final) with or without rPLTP $(5 \mu \mathrm{g} /$ $\mathrm{mL}$, final) in the assay buffer was pre-incubated in the presence or absence of VLDL ( $25 \mu \mathrm{g}$ protein $/ \mathrm{mL}$, final) for $15 \mathrm{~min}$ at $37^{\circ} \mathrm{C}$, followed by the addition of factor XIIa $(0.1 \mathrm{nM}$, final) and incubated for optimal times. The kallikrein activity generated was measured as amidolytic activity for S2302 (0.4 mM, final).

\section{Factor XII binding to PLTP}

Binding was assessed by surface plasmon resonance (SPR) analysis using a BIAcore 3000 biosensor system. An anti-His tag monoclonal antibody was covalently immobilized on the carboxymethylated dextran (CM5) sensor chip (BIAcore) using amine coupling chemistry according to the manufacturer's instructions. A nonreactive mouse IgG was used as a control for nonspecific binding. rPLTP with a C-terminal His-tag $(100 \mu \mathrm{g} / \mathrm{ml})$ was diluted in $50 \mathrm{mM}$ Hepes, $150 \mathrm{mM} \mathrm{NaCl}$, and $5 \mathrm{mM} \mathrm{CaCl}_{2}$ $(\mathrm{pH}$ 7.4) and injected at a flow rate of $10 \mu \mathrm{L} / \mathrm{min}$ with 10 min contact time generating a response. Then, each concentration of factor XII was injected in this buffer for $1.5 \mathrm{~min}$ at a flow rate of $5 \mu \mathrm{L} / \mathrm{min}$. After each Factor XII sensorgram was obtained, the His tag-antibody surface was regenerated with $10 \mathrm{mM}$ glycine $/ \mathrm{HCl}, \mathrm{pH} 2.5$, and a new injection of His-tag PLTP was used to regenerate the surface. Any influence of mass transport effects was discounted from the results of binding and dissociation at different flow rates. Data analysis was performed by using BIAevaluation software 3.0 (BIAcore). The association and dissociation phases of all 'sensorgrams' were fitted globally. Rate constants for association $\left(\mathrm{k}_{\mathrm{a}}\right)$ and dissociation $\left(\mathrm{k}_{\mathrm{d}}\right)$ were obtained by globally fitting the data from five to six injections of factor XII (0-750 $\mathrm{nM}$ ) by using the BIAevaluation software version 3.2, using the simple Langmuir binding model.

\section{VTE study group}

The Scripps Venous Thrombosis Registry is an ongoing case-control study of risk factors for VTE as described [41]. Inclusion criteria for this study included age at thrombosis $<55$ years old, $>3$ months since diagnosis of acute thrombosis, a life expectancy of at least 3 years and no lipid lowering medications or cancer. Age matched ( \pm 2 years) healthy male controls were recruited through the GCRC blood donation program at Scripps. The protocol was approved by the Institutional Review Board of Scripps Clinic and subjects provided written informed consent. Forty of 49 VTE patients (82\%) presented with idiopathic VTE, defined as events that did not occur within 90 days after surgery, trauma, or major immobilization. In this study, male idiopathic VTE patients $(n=40)$ and controls $(N=40)$ were analyzed for PLTP activity and mass (Additional file 1: Table S1).

\section{Clinical analytes}

Serum lipid profile data were obtained from the routine clinical lab using standard techniques.

Lipoprotein subclass particle concentrations were measured by Nuclear Magnetic Resonance Spectroscopy (NMR) at LipoScience, Inc (Raleigh,NC) [41]. PLTP activity (total plasma activity) and mass were determined as described [23, 26].

\section{Statistical analysis}

Data for VTE patients and controls was compared for median values using the Mann-Whitney test using Prism ${ }^{\mathrm{Tm}}$ 
4.0 software (Graph Pad Software Inc., San Diego, CA). Odds ratios for VTE were determined with a logistic regression model using Minitab software. The difference was considered significant when $\mathrm{p}$ was $<0.05$.

\section{Results}

Effects of rPLTP on sulfatide-induced plasma thrombin generation

When added to plasma in increasing amounts, rPLTP markedly reduced the total amount of thrombin generation and prolonged the lag time for thrombin generation in plasma activated by sulfatides (Fig. 1a). In contrast, rPLTP had no effect or only a very slight effect on factor XIainduced or tissue factor-induced thrombin generation in plasma (Figs. 1b and c). This suggests that rPLTP significantly inhibits the factor XII-dependent contact activation reactions but not the intrinsic or extrinsic coagulation pathways activated by factor XIa or tissue factor.

Effect of increasing sulfatide concentration on inhibition of thrombin generation in plasma by rPLTP

To study if the effect of rPLTP is due to interactions of rPLTP with sulfatide, the effect of rPLTP was tested under various concentrations of sulfatide $(2 \mu \mathrm{M}, 20 \mu \mathrm{M}$ and $100 \mu \mathrm{M})$. The ability of rPLTP to inhibit thrombin generation was not neutralized or significantly altered by increasing the amounts of sulfatide (e.g., from $2 \mu \mathrm{M}$ to $100 \mu \mathrm{M})$ (Fig. 2), indicating that the major effect of PLTP was independent of sulfatide concentration. Besides sulfatides, other negatively charged surfaces (e.g., kaolin, dextran sulfate, etc.) also stimulate contact activation. When contact activation was stimulated by kaolin or dextran sulfate, rPLTP did not inhibit thrombin generation in plasma (Additional file 1: Figure S1).

\section{Effect of rPLTP on sulfatide-induced kallikrein generation} in plasma

To study the effect of rPLTP on contact activation reactions, the sulfatide-induced activation of prekallikrein/factor XII in plasma was evaluated at various time points. In the assay system employed, contact activation was monitored by kallikrein generation. In controls, rPLTP $(0-20 \mu \mathrm{g} / \mathrm{ml})$ did not directly affect the kallikrein amidolytic activity towards the chromogenic substrate S2302 (data not shown). rPLTP delayed generation of plasma kallikrein activity by sulfatides in plasma (Fig. 3a) and did so in a concentrationdependent fashion $\left(\mathrm{IC}_{50}=0.69 \mu \mathrm{g} / \mathrm{ml}\right.$ ) (Fig. 3b). These data show that rPLTP inhibits contact phase activation in the coagulation system.

\section{Effect of rPLTP on contact phase activation}

Contact phase activation in the coagulation system is enhanced by factor XII autoactivation and by the reciprocal activations of factor XII by kallikrein and of prekallikrein

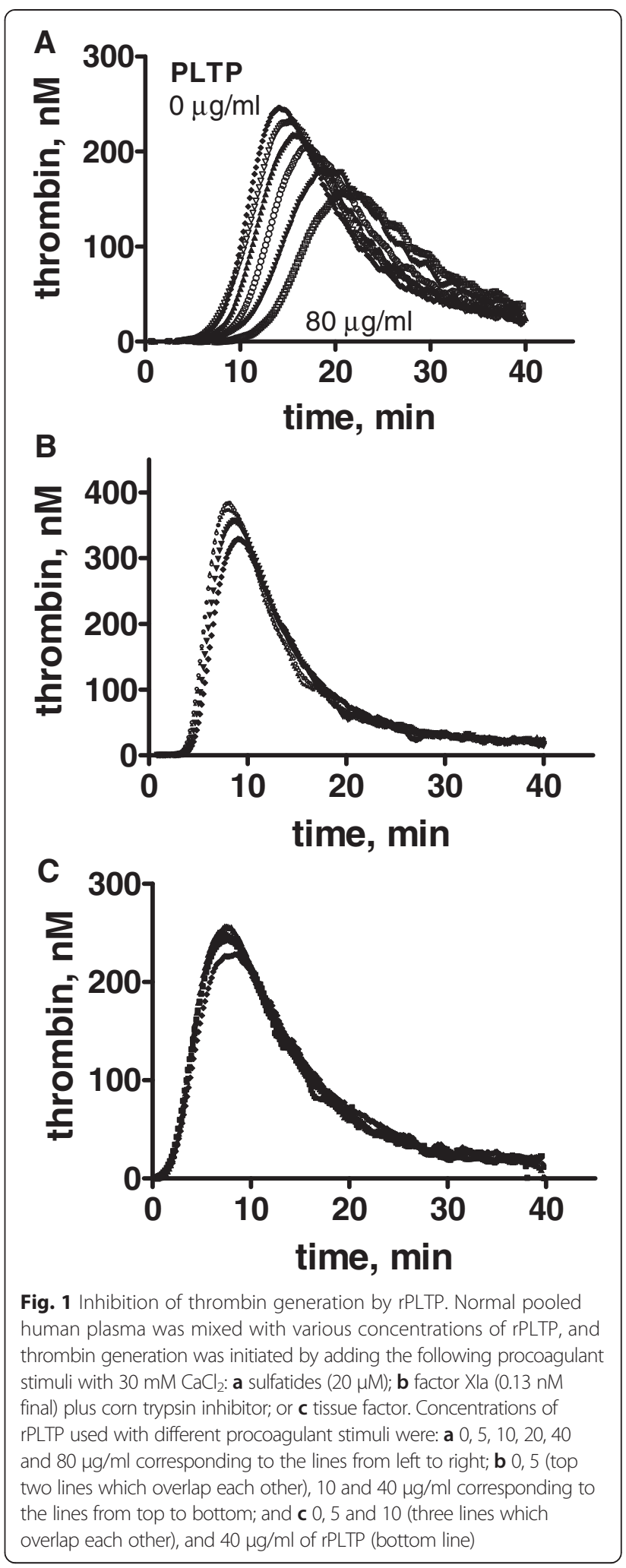

by factor XIIa. When the effect of rPLTP on contact activation reactions was studied in assays containing only purified protein components, rPLTP did not affect factor 


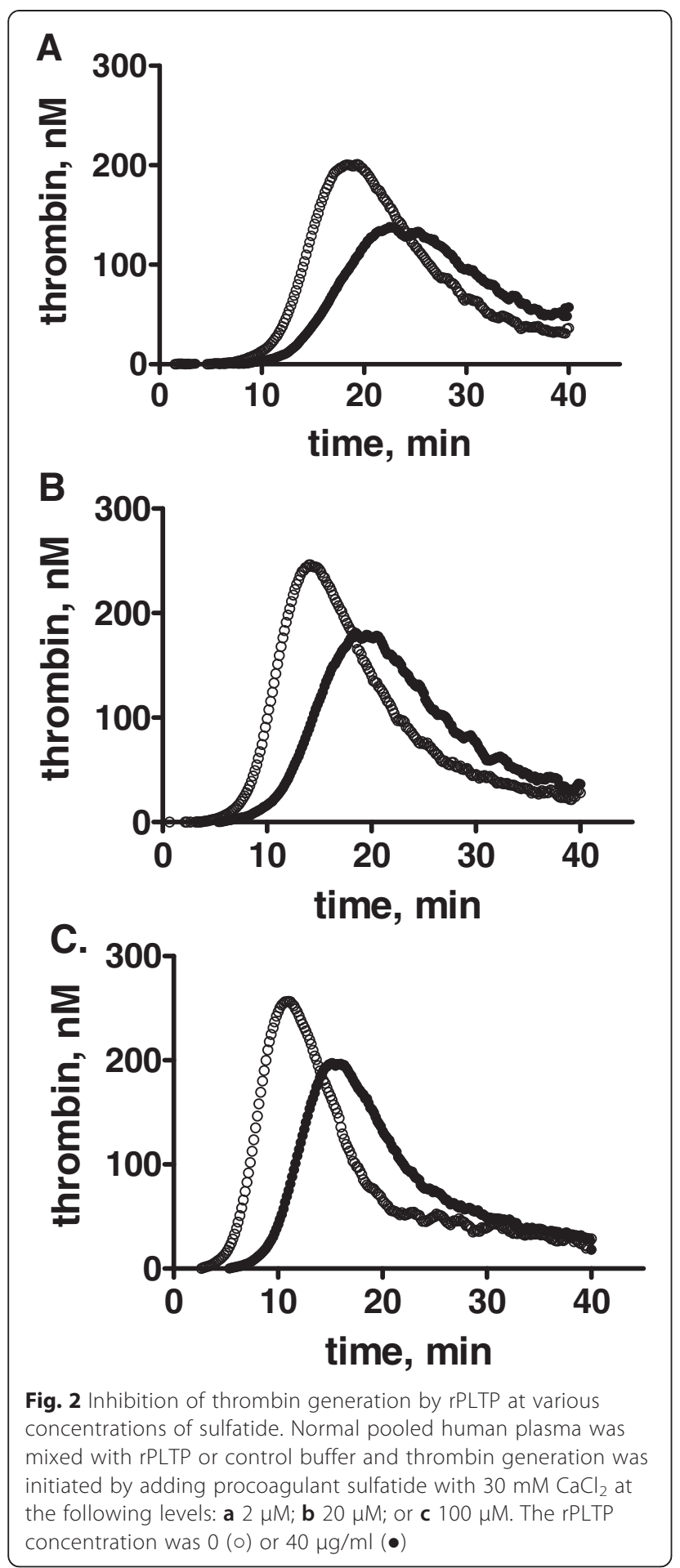

XII auto-activation stimulated by sulfatide, factor XII activation by kallikrein, or prekallikrein activation by factor XIIa (Additional file 1: Figure S2, A, B, and C, respectively). However, when VLDL was added into the purified reaction component mixture, rPLTP inhibited factor XII autoactivation (Fig. 4a) in a concentrationdependent fashion $\left(\mathrm{IC}_{50}=1.2 \mu \mathrm{g} / \mathrm{ml}\right.$ ) (Fig. $4 \mathrm{~b}$ ). Neither

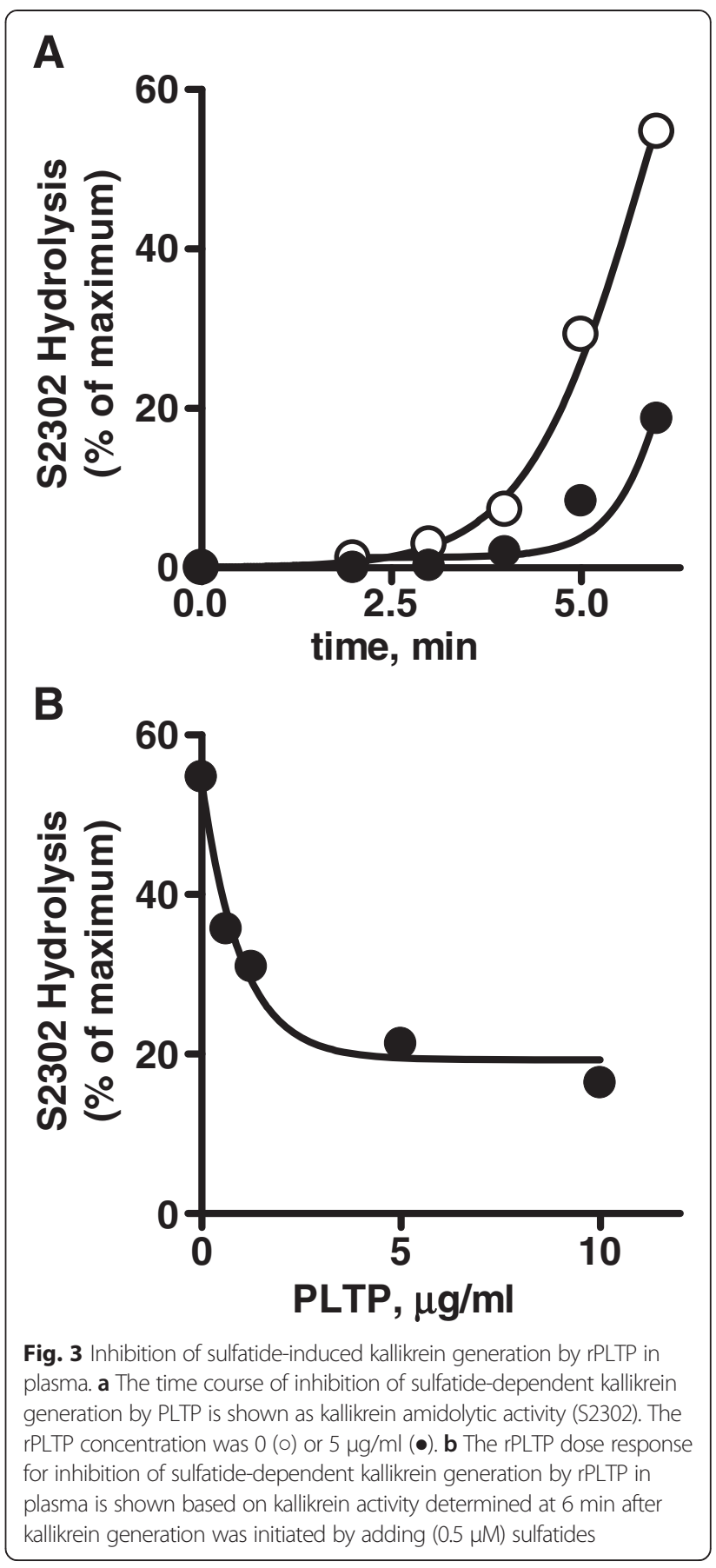

Factor XII activation by kallikrein nor prekallikrein activation by factor XIIa was affected by rPLTP in the absence or presence of VLDL (Additional file 1: Figure S3 A and B). The amidolytic activity of FXIIa or kallikrein towards S2302 was not inhibited by PLTP even in the absence or presence of VLDL (data not shown).

rPLTP binding to factor XII

SPR was used to study the binding of factor XII to rPLTP. Factor XII bound to immobilized rPLTP whereas 


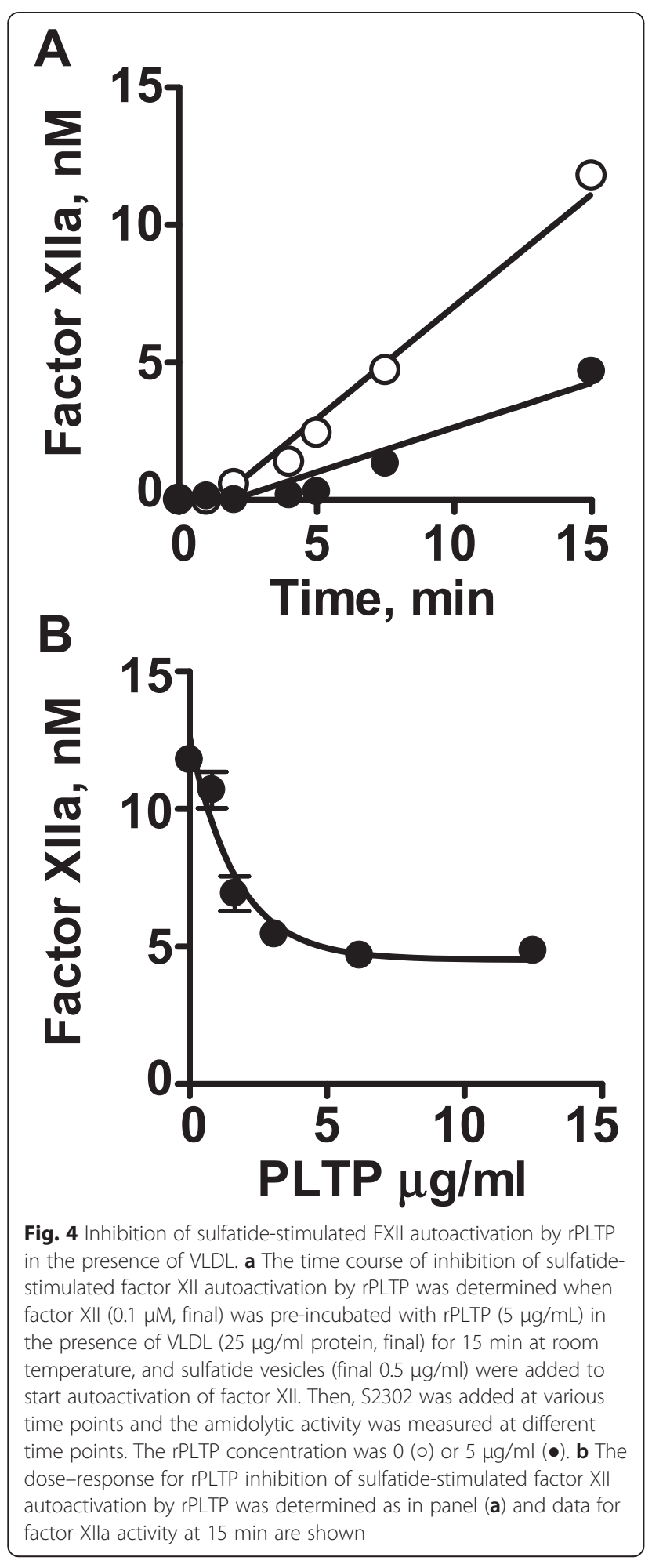

no binding of factor XI (up to $500 \mathrm{nM}$ ) to rPLTP was detected by SPR (Fig. 5). Based on the data analysis, rate constants $\mathrm{k}_{\text {on }}$ and $\mathrm{k}_{\text {off }}$ for binding of factor XII to rPLTP and its apparent $\mathrm{Kd}$ were $0.31 \times 10^{5}(1 / \mathrm{Ms}), 60 \times 10^{-4}$ $(1 / \mathrm{s})$ and $190 \mathrm{nM}$, respectively.

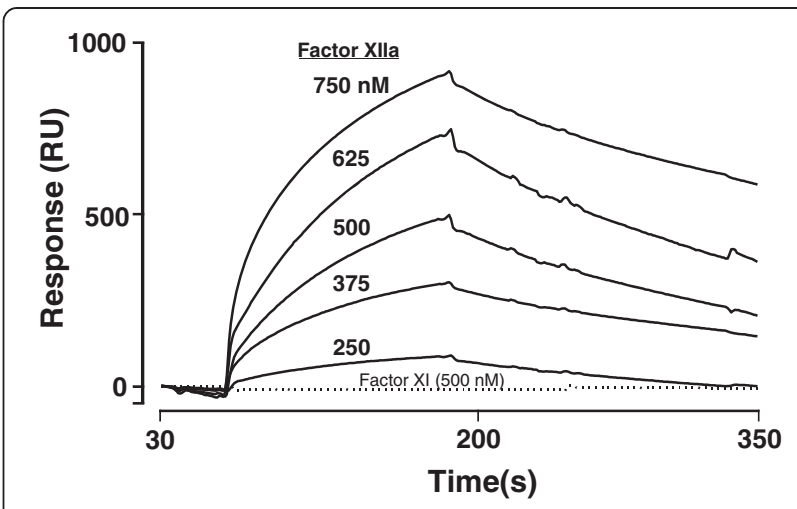

Fig. 5 Binding of Factor XII to rPLTP using SPR. SPR was used to monitor binding of factor XII (250-750 nM) to immobilized rPLTP. Sensorgrams represent the binding of factor XII (from top to bottom at 750, 625, 500, 375, $250 \mathrm{nM}$, as indicated. In controls, purified Factor XI (500 nM) (dotted line) did not exhibit any binding to immobilized rPLTP

\section{Association of venous thrombotic disease with PLTP} activity and mass

Because rPLTP can inhibit thrombin generation in plasma, we postulated that low plasma levels of PLTP may be linked to VTE. In a pilot study of subjects from the Scripps VTE Registry, we assessed whether low levels of plasma PLTP are associated with VTE risk. There was no significant difference in the median values of PLTP activity or PLTP mass levels in 40 adult male VTE patients compared to matched controls $(p=0.57$ and 0.59 , respectively) (data not shown). When the quartile-based odds ratio (OR) for the association of VTE with PLTP activity was calculated by comparing quartile 1 (lowest PLTP) with quartiles 2-4 (Table 1), a low level of PLTP activity was not statistically significantly associated with increased VTE risk although the OR was 2.2 (95\%CI: 0.78-5.9) (Table 1, model I). Some plasma parameters which may be associated with both PLTP level and VTE risk, namely BMI and HDL-C (Additional file 1: Table S1) (23), and some other lipids possibly linked to procoagulant activities which may be altered by PLTP were used for adjustment of the OR. When adjusted for BMI and HDL-C, the OR for low PLTP activity was 2.7 (95\%CI: $0.91-7.8, \quad p=0.07)$ (Table 1, model II), and further adjustment for LDL-C and triglyceride (TG) improved the OR to 5.2 (95\%CI: $1.5-19, \mathrm{p}=0.01$ ) (Table 1 , model IV). Particularly significant was the finding that the low PLTP activity level was highly significantly associated with the risk of VTE with an $\mathrm{OR}=12$ (95\%CI: 2.4-56, $p=0.002)$ after further adjustment for the known VTE risk factors, FV Leiden and prothrombin nt20210A (Table 1, model V). When VLDL particle concentrations measured by NMR was used for the correction instead of TG, the ORs were similar to the values with triglyceride $(\mathrm{OR}=5.3(95 \% \mathrm{CI}$ : $1.5-19)$ for 
Table 1 Quartile-based Odds Ratio (OR) for association of low PLTP activity ( $\leq 25$ th percentile)

\begin{tabular}{|c|c|c|c|c|}
\hline \multirow[b]{2}{*}{ Model and adjustments } & \multicolumn{2}{|l|}{ PLTP activity } & \multicolumn{2}{|l|}{ PLTP mass } \\
\hline & OR $(95 \% \mathrm{Cl})$ & $\mathrm{p}$ & OR $(95 \% \mathrm{Cl})$ & $p$ \\
\hline I. No adjustment & $2.2(0.78-5.9)$ & 0.15 & $1.3(0.46-3.8)$ & 0.59 \\
\hline II. BMI + HDL & $2.7(0.91-7.8)$ & 0.07 & $0.53(0.14-2.1)$ & 0.55 \\
\hline III. II + FV Leiden + prothrombin nt20210A & $3.5(1.1-12)$ & 0.04 & $0.49(0.1-1.8)$ & 0.37 \\
\hline IV II + LDL-C + TG & $5.2(1.5-19)$ & 0.01 & $0.84(0.23-3.0)$ & 0.79 \\
\hline V. III+ LDL-C + TG & $12(2.4-56)$ & 0.002 & $0.62(0.15-2.6)$ & 0.52 \\
\hline
\end{tabular}

The odds ratios (OR) for unprovoked VTE with low levels ( $\leq 25$ th percentile) of PLTP activity and PLTP mass are shown. Models were adjusted by variables as indicated, including BMI, HDL-C, LDL-C and TG which were used as continuous values and factor V Leiden and prothrombin nt20210A

model IV and OR $=11(95 \% \mathrm{CI}$ : 2.3-52) for model V, respectively). The high PLTP levels ( $>75$ percentile) was not protective against VTE $(\mathrm{OR}=1.4$ (95\%CI: $0.55-3.8)$, $p=0.53)$ even after adjustment described above (OR = 0.75 (95\%CI: $0.23-2.5$ ) for model IV and $\mathrm{OR}=0.65$ (95\%CI: 0.17-2.5) for model V, respectively). PLTP mass was not associated with the risk of VTE based on quartile-based OR analysis in any of the models summarized in Table 1.

\section{Discussion}

In this study we showed that a recombinant plasma protein, rPLTP, can inhibit sulfatide-induced thrombin generation and contact activation in plasma, implying that it may function as an anticoagulant factor where contact activation is involved. This activity of rPLTP was not apparent when thrombin generation in plasma was triggered by factor XIa or tissue factor, implying a direct effect of rPLTP on contact activation reactions. Factor XII is the key enzyme for contact activation [1-7] and, indeed, we found that factor XII binds directly to rPLTP, thereby providing a starting point for mechanistic studies for the actions of rPLTP.

Interestingly, rPLTP did not inhibit contact activation in plasma stimulated by two other negatively charged activators of the contact system, dextran sulfate and kaolin, further implying that the anticoagulant actions of rPLTP were not due to a nonspecific blocking of negative charges. These findings might be supported by reports that mechanisms responsible for surface activation triggered by different negatively charged molecules (e.g., sulfatide and kaolin) differ from each other as regards the molecular interaction with the contact factors $[11,14]$. However, the details for the mechanistic relations of PLTP to surface materials for contact activation of coagulation including other naturally occurring negatively charged surfaces effect (e.g., misfolded proteins, and polyphosphates) need to be evaluated in future studies.

The requirement of VLDL, which also could provide surface for contact pathway of coagulation system [42], for the inhibition of sulfatide-induced autoactivation of factor XII by rPLTP in purified protein reaction mixtures may reflect direct or indirect effects of VLDL on factor XII and/or rPLTP. Recent work shows that a significant fraction of PLTP is bound to VLDL in plasma [39], so the ability of rPLTP to inhibit sulfatide-induced contact activation in plasma or factor XII autoactivation likely reflects actions of a PLTP $\bullet V L D L$ complex in plasma. Extensive and detailed mechanistic studies using rPLTP, factor XII and $\alpha$-factor XIIa plus VLDL and many proteins that associate with VLDL [43] would be needed for studies to clarify details and elucidate the structural basis for the effects of these molecules on contact activation or factor XII autoactivation. Further, other lipoproteins (i.e., HDL and LDL), which were not tested here, could also possibly contribute to the anticoagulant activity of PLTP.

Binding studies using purified proteins show direct interactions between factor XII and PLTP. For this protein-protein interaction, the apparent $\mathrm{Kd}$ value of $190 \mathrm{nM}$ is below the plasma level of factor XII which is $300 \mathrm{nM}$ [44] but above the plasma level of PLTP at $25 \mathrm{nM}$ [19]. Perhaps reflecting this modest value of apparent Kd, PLTP alone does not inhibit sulfatideinduced factor XII autoactivation in purified reaction systems. However, when VLDL was added to the purified system, PLTP does inhibit Factor XII autoactivation, showing additional plasma components are needed. Thus, because VLDL particles carry many associated proteins in addition to PLTP [43], we speculate that the whole VLDL particles or one or more proteins in the VLDL interactome enhances affinity of PLTP for factor XIIa which at very low levels is responsible for triggering factor XII autoactivation. Additionally, factor XII conformational changes induced by sulfatide or zinc ions [14] might influence the affinity of factor XIIa for PLTP. However, mechanisms for inhibition of factor XII autoactivation by PLTP in plasma are not completely clear and they need further clarifications including the potential influences of VLDL, sulfatide, or zinc ions on factor XIIa-PLTP binding interactions.

Factor XII is not required for normal hemostasis in man or various animals. However, studies of thrombosis injury models in mice genetically deficient in factor XII 
or XI suggest that factor XII-dependent thrombin generation via the intrinsic coagulation pathway can significantly contribute in vivo to fibrin formation and thrombosis including a pulmonary embolism model [3-7]. This concept plus the ability of PLTP to inhibit thrombin generation in plasma led us to assay PLTP activity and mass in plasmas of a young adult male VTE cohort that we have previously described [23, 41]. The initial analysis of our data without any adjustments for variables failed to show any association of plasma PLTP activity and mass levels with VTE risk. However, a very significant association between low PLTP activity and VTE became apparent after making adjustments for various lipoprotein levels (Table 1, models IV and V) or by analyzing separately the subgroup of normolipidemic patients (Additional file 1: Figure S4). It appears that levels of plasma lipoproteins, which are indeed related to PLTP-mediated phospholipid transfer activity [23], can mask the association of PLTP activity with VTE risk. Overall, our finding here is consistent with the concept that active PLTP molecules, putatively in VLDL $\bullet$ PLTP complexes [43], contribute to the multiple, highly varied antithrombotic activities of plasma. One notes that major limitations of this pilot VTE study include the low number of subjects, the age of subjects under 55 years old, and the absence of female cohorts.

Factor XII-dependent contact activation not only might contribute in vivo to fibrin formation and excessive thrombosis including pulmonary embolism model [3-7] but also might contribute to inflammation and pathologies via bradykinin formation and complement activation $[5,6$, 45]. Thus, inhibition of contact activation mediated by PLTP might inhibit not only thrombosis but also inflammatory processes stimulated or supported by contact activation. In this regard, it is interesting that PLTP was shown to exert anti-inflammatory activities [46, 47], although no information relating PLTP's anti-inflammatory actions to any pro-inflammatory actions due to contact activation have been described.

\section{Conclusions}

We found that PLTP is an inhibitor of sulfatide-initiated factor XII-dependent thrombin generation by inhibiting factor XII autoactivation and that VLDL appears to contribute to this activity of PLTP. After adjustments for two thrombophilic genetic risk factors and for lipoprotein and lipid parameters known to be affected by plasma PLTP activity, low plasma PLTP activity was very significantly associated with increased risk of VTE in a small pilot study of young adult normolipidemic males. Both the functionally significant interactions between PLTP and factor XII and the relationship between PLTP activity and VTE merit further detailed investigations.

\section{Additional file}

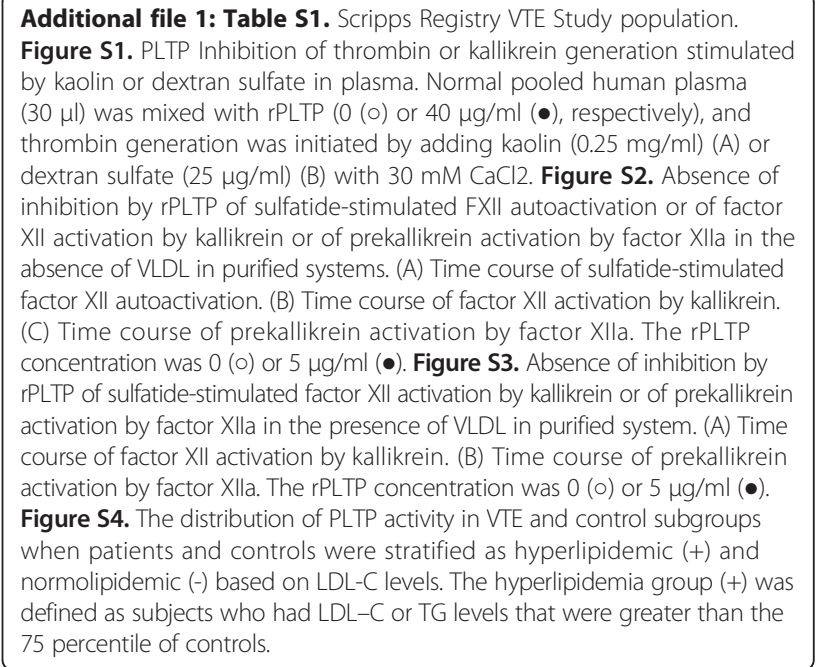

Competing interests

The authors declare that they have no competing interests.

\section{Authors' contributions}

$J H G, H D$ and JJA participated in the conception of the study. GW and MCC were responsible for rPLTP preparation and quantification of plasma levels of PLTP mass and activity. HD was responsible for performing experiments with PLTP activity and statistical analysis. DJE was responsible for consenting the VTE patients and controls and for obtaining blood specimens. YB and JAF were responsible for performing SPR experiments. HD, DJE and JHG were responsible for writing the manuscript. All authors read and approved the final manuscript.

\section{Acknowledgments}

This work was supported by grants HL021544 (JHG) and HL030086 (JJA).

\section{Author details}

${ }^{1}$ Department of Molecular and Experimental Medicine, The Scripps Research Institute, MEM180, 10550 North Torrey Pines Rd., La Jolla, CA 92037, USA.

2Division of Metabolism, Endocrinology, and Nutrition, Northwest Lipid Metabolism and Diabetes Research Laboratories, Department of Medicine, University of Washington, Seattle, WA 98109, USA. ${ }^{3}$ Current Address: Department of Biochemistry, College of Medicine and Health Sciences, SQ University, Muscat, Oman.

Received: 2 February 2015 Accepted: 20 May 2015 Published online: 16 July 2015

\section{References}

1. Davie EW, Fujikawa K, Kisiel W. The coagulation cascade: initiation, maintenance, and regulation. Biochemistry. 1991;30:10363-70.

2. Mann KG. Thrombin formation. Chest. 2003;124:4S-10S.

3. Renné T, Pozgajová M, Grüner S, Schuh K, Pauer HU, Burfeind P, et al. Defective thrombus formation in mice lacking coagulation factor XII. J Exp Med. 2005;202:271-81.

4. Björkqvist J, Nickel KF, Stavrou E, Renné T. In vivo activation and functions of the protease factor XII. Thromb Haemost. 2014;112:868-75.

5. Schmaier $A H$, Larusch G. Factor XIl: new life for an old protein. Thromb Haemost. 2010;104:915-8.

6. Schmaier AH. The elusive physiologic role of Factor XII. J Clin Invest. 2008:118:3006-9.

7. Cheng Q, Tucker El, Pine MS, Sisler I, Matafonov A, Sun MF, et al. A role for factor Xlla-mediated factor XI activation in thrombus formation in vivo. Blood. 2010;116:3981-9.

8. Tans G, Griffin JH. Properties of sulfatides in factor-XII-dependent contact activation. Blood. 1982;59:69-75. 
9. Tans G, Rosing J, Griffin JH. Sulfatide-dependent autoactivation of human blood coagulation Factor XII (Hageman Factor). J Biol Chem. 1983;258:8215-22.

10. Rosing J, Tans G, Griffin JH. Surface-dependent activation of human factor XII (Hageman factor) by kallikrein and its light chain. Eur J Biochem. 1985;151:531-8.

11. Shimada T, Sugo T, Kato H, Yoshida K, Iwanaga S. Activation of factor XII and prekallikrein with polysaccharide sulfates and sulfatides: comparison with kaolin-mediated activation. J Biochem. 1985:97:429-39.

12. Tans $G$, Rosing J, Berrettini M, Lämmle B, Griffin JH. Autoactivation of human plasma prekallikrein. J Biol Chem. 1987;262:11308-14.

13. Tans G, Janssen-Claessen T, Rosing J, Griffin JH. Studies on the effect of serine protease inhibitors on activated contact factors. Application in amidolytic assays for factor XIla, plasma kallikrein and factor Xla. Eur J Biochem. 1987:164:637-42.

14. Røjkjaer R, Schousboe I. The surface-dependent autoactivation mechanism of factor XII. Eur J Biochem. 1997;243:160-6.

15. Maas C, Govers-Riemslag JW, Bouma B, Schiks B, Hazenberg BP, Lokhorst $H M$, et al. Misfolded proteins activate factor XII in humans, leading to kallikrein formation without initiating coagulation. J Clin Invest. 2008;118:3208-18.

16. Griffin JH, Fernandez JA, Deguchi H. Plasma lipoproteins, hemostasis and thrombosis. Thromb Haemost. 2001;86:386-94.

17. Mineo C, Deguchi H, Griffin JH. Shaul PW. Circ Res. 2006;98:1352-64.

18. Deguchi H, Fernandez JA, Griffin JH. Plasma cholesteryl ester transfer protein and blood coagulability. Thromb Haemost. 2007;98:1160-4.

19. Albers JJ, Vuletic S, Cheung MC. Role of plasma phospholipid transfer protein in lipid and lipoprotein metabolism. Biochim Biophys Acta. 1821;2012:345-57.

20. Huuskonen J, Ekström M, Tahvanainen E, Vainio A, Metso J, Pussinen P, et al. Quantification of human plasma phospholipid transfer protein (PLTP): relationship between PLTP mass and phospholipid transfer activity. Atherosclerosis. 2000;151:451-61.

21. Oka T, Kujiraoka T, Ito M, Nagano M, Ishihara M, Iwasaki T, et al. Measurement of human plasma phospholipid transfer protein by sandwich ELISA. Clin Chem. 2000;46:1357-64

22. Siggins S, Kärkkäinen M, Tenhunen J, Metso J, Tahvanainen E, Olkkonen VM, et al. Quantitation of the active and low-active forms of human plasma phospholipid transfer protein by ELISA. J Lipid Res. 2004;45:387-95.

23. Cheung MC, Wolfbauer G, Deguchi H, Fernández JA, Griffin JH, Albers JJ. Biochim. Biophys Acta. 2009;1791:206-11.

24. Tall AR, Krumholz S, Olivecrona T, Deckelbaum RJ. Plasma phospholipid transfer protein enhances transfer and exchange of phospholipids between very low density lipoproteins and high density lipoproteins during lipolysis. J Lipid Res. 1985;26:842-51.

25. Tollefson JH, Ravnik S, Albers JJ. Isolation and characterization of a phospho-lipid transfer protein (LTP-II) from human plasma. J Lipid Res. 1988:29:1593-602.

26. Cheung MC, Wolfbauer G, Albers JJ. Plasma phospholipid mass transfer rate relationship to plasma phospholipid and cholesteryl ester transfer activities and lipid parameters. Biochim Biophys Acta. 1996;1303:103-10.

27. Nishida HI, Nishida T. Phospholipid transfer protein mediates transfer of not only phosphotidylcholine but also cholesterol from phosphotidylcholinecholesterol vesicles to high density lipoproteins. J Biol Chem. 1997;272:6959-64.

28. Tu A-Y, Nishida HI, Nishida T. High-density lipoprotein conversion mediated by human plasma phospholipid transfer protein. J Biol Chem. 1993:268:23098-105.

29. Albers JJ, Wolfbauer G, Cheung MC, Day JR, Ching AF, Lok S, et al. Functional expression of human and mouse plasma phospholipid transfer protein: effect of recombinant and plasma PLTP on HDL subspecies. Biochim Biophys Acta. 1995;1258:27-34.

30. von Eckardstein A, Jauhiainen M, Huang Y, Metso J, Langer C, Pussinen P, et al. Phospholipid transfer protein mediated conversion of high density lipoproteins generates prebeta-HDL. Biochim Biophys Acta. 1996;1301:255-62.

31. Setälä NL, Holopainen JM, Metso J, Wiedmer SK, Yohannes G, Kinnunen PK, et al. Interfacial and lipid transfer properties of human phospholipid transfer protein: implications for the transfer mechanism of phospholipids. Biochemistry. 2007:46:1312-9.

32. Vergeer M, Boekholdt SM, Sandhu MS, Ricketts SL, Wareham NJ, Brown MJ, et al. Genetic variation at the phospholipid transfer protein locus affects its activity and high-density lipoprotein size and is a novel marker of cardiovascular disease susceptibility. Circulation. 2010;122:470-7.

33. Schlitt A, Bickel C, Thumma P, Blankenberg S, Rupprecht HJ, Meyer J, et al. High plasma phospholipid transfer protein levels as a risk factor for coronary artery disease. Arterioscler Thromb Vasc Biol. 2003;23:1857-62.
34. Schlitt A, Blankenberg S, Bickel C, Lackner KJ, Heine GH, Buerke M, et al. PLTP activity is a risk factor for subsequent cardiovascular events in CAD patients under statin therapy: the AtheroGene study. J Lipid Res. 2009;50:723-9.

35. Schgoer W, Mueller T, Jauhiainen M, Wehinger A, Gander R, Tancevski I, et al. Low phospholipid transfer protein (PLTP) is a risk factor for peripheral atherosclerosis. Atherosclerosis. 2008;196:219-26.

36. de Vries R, Dallinga-Thie GM, Smit AJ, Wolffenbuttel BH, van Tol A, Dullaart RP. Elevated plasma phospholipid transfer protein activity is a determinant of carotid intima-media thickness in type 2 diabetes mellitus. Diabetologia. 2006:49:398-404.

37. Tzotzas T, Desrumaux C, Lagrost L. Plasma phospholipid transfer protein (PLTP):review of an emerging cardiometabolic risk factor. Obes Rev. 2009;10:403-11.

38. Yatsuya H, Tamakoshi K, Hattori H, Otsuka R, Wada K, Zhang H, et al. Serum phospholipid transfer protein mass as a possible protective factor for coronary heart diseases. Circ J. 2004;68:11-6.

39. Oram JF, Wolfbauer G, Tang C, Davidson WS, Albers JJ. An amphipathic helical region of the $\mathrm{N}$-terminal barrel of phospholipid transfer protein is critical for ABCA1-dependent cholesterol efflux. J Biol Chem. 2008;283:11541-9.

40. Hron G, Kollars M, Binder BR, Eichinger S, Kyrle PA. Identification of patients at low risk for recurrent venous thromboembolism by measuring thrombin generation. JAMA. 2006;296:397-402.

41. Deguchi H, Pecheniuk NM, Elias DJ, Averell PM, Griffin JH. High-density lipoprotein deficiency and dyslipoproteinemia associated with venous thrombosis in men. Circulation. 2005;112:893-9.

42. Klein S, Spannagl M, Engelmann B. Phosphatidylethanolamine participates in the stimulation of the contact system of coagulation by very-low-density lipoproteins. Arterioscler Thromb Vasc Biol. 2001;21:1695-700.

43. Dashty M, Motazacker MM, Levels J, de Vries M, Mahmoudi M, Peppelenbosch MP, et al. Proteome of human plasma very low-density lipoprotein and low-density lipoprotein exhibits a link with coagulation and lipid metabolism. Thromb Haemost. 2014;111:518-30.

44. Cochrane CG, Griffin JH. The biochemistry and pathophysiology of the contact system of plasma. Adv Immunol. 1982:33:241-306.

45. Kaplan AP, Joseph K. Pathogenic mechanisms of bradykinin mediated diseases: dysregulation of an innate inflammatory pathway. Adv Immunol. 2014;121:41-89.

46. Vuletic S, Dong W, Wolfbauer G, Tang C, Albers JJ. PLTP regulates STAT3 and NFKB in differentiated THP1 cells and human monocyte-derived macrophages. Biochim Biophys Acta. 1813;2011:1917-24.

47. Brehm A, Geraghty P, Campos M, Garcia-Arcos I, Dabo AJ, Gaffney A, et al. Cathepsin G degradation of phospholipid transfer protein (PLTP) augments pulmonary inflammation. FASEB J. 2014;28:2318-31.

\section{Submit your next manuscript to BioMed Central and take full advantage of:}

- Convenient online submission

- Thorough peer review

- No space constraints or color figure charges

- Immediate publication on acceptance

- Inclusion in PubMed, CAS, Scopus and Google Scholar

- Research which is freely available for redistribution 